\title{
Positive expression of Midkine predicts early recurrence and poor prognosis of initially resectable combined hepatocellular cholangiocarcinoma
}

\author{
Ming-Chun Ma ${ }^{1,2+}$, Yi-Ju Chen ${ }^{3 \dagger}$, Tai-Jan Chiu ${ }^{1,2,4,5}$, Jui Lan ${ }^{6}$, Chien-Ting Liu ${ }^{1,2}$, Yi-Ching Chen ${ }^{1,2}$, Hsin-Ho Tien ${ }^{7}$
} and Yen-Yang Chen ${ }^{1,2,4^{*}}$

\begin{abstract}
Background: Post-surgical prognosis is usually poor for combined hepatocellular cholangiocarcinoma (CHCC-CC), a rare primary liver cancer. Although midkine (MK) is a prognostic biomarker for several known cancers, it is not known whether it can be used as such in resectable CHCC-CC. This study examined whether MK expression can predict recurrence and survival in patients with resectable CHCC-CC.

Methods: We retrospectively enrolled 52 patients with resectable CHCC-CC who had received curative hepatic resections. MK expression was assessed in post-surgical immunohistochemical studies of specimens in paraffin blocks. Clinical outcomes were analyzed from medical records.

Results: Two-year disease-free and three-year overall survival rates were $42.1 \%$ and $44.6 \%$. MK was expressed in 30 patients. Univariate analysis showed patients positively expressing MK had a significantly poorer 2-year disease free and three-year overall survival. Multivariate analysis found positive MK expression independently predicted recurrence.
\end{abstract}

Conclusions: Positive expression of MK predicts poor prognosis in patients with resectable CHCC-CC.

Keywords: Combined hepatocellular cholangiocarcinoma (CHCC-CC), Midkine (MK), Early recurrence, Prognosis

\section{Background}

Hepatocellular carcinoma (HCC), the most common primary liver malignancy, originates from hepatocytes. Cholangiocarcinoma (CC), the second most common, originates from bile duct epithelial cells. Combined hepatocellular cholangiocarcinoma (CHCC-CC), a rare primary liver cancer consisting of two components, HCC and CC, accounts for $1 \%$ to $14.3 \%$ of all primary malignant liver tumors [1-9]. To date, complete tumor resection is its only possible cure. It is difficult to precisely diagnose this disease preoperatively.

\footnotetext{
* Correspondence: chen.y9964@gmail.com

${ }^{\dagger}$ Equal contributors

'Division of Hematology-Oncology, Department of Internal Medicine,

Kaohsiung Chang Gung Memorial Hospital, 123 Ta-Pei Road, Niaosong

District, Kaohsiung 833, Taiwan

${ }^{2}$ Chang Gung University College of Medicine, Kaohsiung, Taiwan

Full list of author information is available at the end of the article
}

Although CHCC-CC is usually diagnosed post-operatively based on pathological findings, immunohistochemical stains have also been used to further confirm the presence of both components $[6,8,10,11]$.

The clinicopathological characteristics and prognosis of patients with $\mathrm{CHCC}-\mathrm{CC}$ after surgery have not been reported in detail because the incidence of this disease is very low and studies on it are scarce. While these studies report conflicting outcomes, most conclude that $\mathrm{CHCC}-\mathrm{CC}$ has a worse prognosis than either HCC or $\mathrm{CC}$ alone [12]. Only a few papers discuss the possible molecular markers that could be used to predict outcome in CHCC-CC [13, 14]. Because the molecules studied were not found to efficaciously predict likelihood of post-surgical $\mathrm{CHCC}-\mathrm{CC}$ recurrence, there remains a need to identify biomarkers that can help 
assess its treatment response as well as predict recurrence and prognosis.

Midkine (MK) is a heparin-binding growth factor weakly expressed or undetectable in normal adult tissue but strongly expressed during embryogenesis [15]. It is expressed at abnormally high levels in several human cancers, including esophagus, gall bladder, pancreas, colorectal, breast, salivary gland and lung carcinomas [16-18]. It has been found to exacerbate disease by promoting many tumor specific functions, including cell growth, tumor cell survival, cell migrations, and carcinogenesis [19-21].

Some studies have investigated the possibility of using MK as a biomarker to predict prognosis and assess response to treatment in oral squamous cell carcinoma and report that its positive expression predicts poor prognosis in patients with various malignant tumors, including head and neck squamous cell carcinoma [22], esophageal squamous cell carcinoma [23] and non-small cell lung cancer [24]. Although MK is known to be overexpressed in hepatocellular carcinoma [25] and cholangiocarcinoma [26], little is known about its significance in $\mathrm{CHCC}-\mathrm{CC}$. Therefore, this study investigated the relationship between its expression and the pathogenesis of CHCC-CC as well as the disease's clinicopathology and survival.

\section{Methods}

\section{Patients}

In this retrospective study, we collected medical records of 52 patients with primary CHCC-CC treated with surgical resection between January 2000 and December 2013 at Kaohsiung Chang Gung Memorial Hospital in Kaohsiung, an industrial city located in southern Taiwan. We also performed immunohistochemical studies of tissue samples collected during surgery. Following Allen and Lisa classification [2], we included only patients with $\mathrm{CHCC}-\mathrm{CC}$ classified as type $\mathrm{C}$ (intimate intermingling of hepatocellular and glandular elements) and type B (contiguous but independent masses of $\mathrm{HCC}$ and $\mathrm{CC}$ ). We excluded patients with type A (separate masses constituting either $\mathrm{HCC}$ or $\mathrm{CC}$ ). CHCC-CC was diagnosed pathologically based on microscope studies of thin-section specimens stained with hematoxylin and eosin. The immunoreactivity of each tumor was confirmed: hepatocyte paraffin 1 (Hep1) antibody and CK-7 (cytokeratin-7) in CHCC-CC.

We retrospectively reviewed the medical records of all the patients with CHCC-CC to obtain medical histories of the present illness. Pre-surgery laboratory data, including tumor markers, serum viral markers, and radiologic evaluations, were recorded. Serum AFP, carbohydrate antigen 19-9, and carcinoembryonic antigen levels before and after tumor resection were recorded, when data were available. If patients had positive findings for $\mathrm{HBsAg}$ and anti-HCV $\mathrm{Ab}$ for more than 6 months, they were assumed to have chronic hepatitis $\mathrm{B}$ and $\mathrm{C}$ infections. Tumor staging was performed in accordance with the American Joint Committee on Cancer staging system sixth edition [27]. Cumulative recurrence rate, median disease-free survival, and median overall survival were calculated. Information was also collected on suspected prognostic factors, including AFP, CEA, and CA-199 levels, seropositivity for $\mathrm{HBsAg}$ or anti-HCV Ab, sex, and tumor stage.

Informed consent was obtained in written form from all study participants and the protocol for this study was approved by the Institutional Review Boards of ChangGung Medical Center (Taiwan) (IRB 103-7412B).

\section{Immunohistochemical study}

A pathologist with expertise in hepatic tumors reviewed macroscopic and microscopic pathological findings and concluded that both HCC cells and ICC cells coexisted in liver tumors and that ICC cells made up more than $10 \%$ of the cells within the tumor. Hematoxylin and Eosin (H\&E) as well as immunohistochemical staining were performed. HCC cells were confirmed based on immunohistological stains of hepatocyte paraffin 1 (Hep1) and ICC cells confirmed based on cytokeratin 7 (CK7).

Immunohistochemical studies were performed to measure protein levels of $\mathrm{MK}$ in paraffin sections of samples obtained from all 52 patients. Samples were fixed with $10 \%$ buffered formalin embedded in paraffin, deparaffinized with xylene and rehydrated in a series of ethanol washes $(100 \mathrm{~d} \%, 90 \%, 80 \%$ and $70 \%)$, and subsequently washed with phosphate-buffered saline (PBS) followed by treatment with $3 \% \mathrm{H} 2 \mathrm{O} 2$ for 30 min to block endogenous peroxidase activity. Sections were then microwaved in $10 \mathrm{mM}$ citrate buffer $(\mathrm{pH}$ 6.0) to unmask the epitopes, incubated with MK monoclonal antibody (Abcam Plc, Cambridge, UK) for $1 \mathrm{~h}$, and washed with PBS. The reaction was visualized using horseradish peroxidase/Fab polymer conjugate (PicTure ${ }^{\text {mi }}$-Plus kit Zymed, South San Francisco, CA) and diaminobenzidine. An antibody assay without the primary antibody was used as a negative control.

MK immunostaining was evaluated independently by two pathologists blinded to the subjects' clinical information. Each specimen was assigned a score of 1 to 4 based on the percentage of positive cells within a field of cells ( $100 \mathrm{x}$ magnification): one for $<5 \%$ of the cells, two for $6-35 \%$ of the cells, three for $36-70 \%$ of the cells, and 4 for $>71 \%$ of the cells. Each specimen also received 
another score of 1 to 4 based on intensity of staining: one for negative staining, two for weak staining, three for moderate staining and four for strong staining. MK expression score was then calculated by multiplying the percentile and intensity scores. A score of $\geq 4$ for $\mathrm{MK}$ protein expression levels indicated the tumor was positive [16].

\section{Immunofluorescent staining}

Immunofluorescent staining was performed on paraffinized tumor samples obtained from the CHCC-CC patients to confirm the expression of CK7 (Abcam) and Hep1(Abcam). After deparaffinization, the sections were blocked with $5 \%$ normal goat serum/PBS at room temperature for $1 \mathrm{~h}$. They were then incubated with primary antibody (CK7; 1:100, Hec-1; $1: 100)$ at $4{ }^{\circ} \mathrm{C}$ overnight. Next they were each washed three times with PBS for $5 \mathrm{~min}$. After incubation with secondary antibodies (1:1000) at room temperature for $1 \mathrm{~h}$, they were each washed three times with PBS for $5 \mathrm{~min}$. They were observed under a confocal microscope.

\section{Statistical analysis}

Patients' demographic information and clinical characteristics were analyzed by MK expression percentile and compared using either Pearson's chi-square test or Fisher's exact test. Overall and disease-free survival were calculated and compared by Log-rank test. (if cell numbers were less than five). Overall and disease-free survival were calculated and compared by Log-rank test. Overall survival was calculated starting from the date that adjuvant treatment was initiated to date of the patient's death or most recent follow-up. Disease-free survival was calculated starting from the date of operation to the date of the first indication of disease progression, disease relapse or death due to any cause. Binary logistic regression was used to analyze the association between positive MK expression and patients' demographic and clinical characteristics. Results were reported as odd ratio (OR) with 95\% confidence interval (95\% CI). Step-wise Coxregression analysis was performed to evaluate whether there was an association between patients' demographic and clinical characteristics and overall and disease-free survival. If any of these variables were found to be significantly associated with these two outcomes $(p<0.05)$ in univariable Cox-regression, we further analyzed their association using multivariable Cox-regression. Results were expressed as hazard ratio (HR) with 95\% confidence interval of $(95 \% \mathrm{CI})$ and corresponding $p$ values. All statistical operations were performed using SPSS 13.0 statistics software (SPSS Inc., Chicago, IL).

\section{Results}

\section{Patient characteristics}

Patients (37 male; $71.2 \%$ ) had a mean age of 58 years \pm 11.35 (range 32-83 years). Thirty-five patients (67.3\%) were found positive for $\mathrm{HbsAg}, 16$ (30.8\%) positive for $\mathrm{HCV} \mathrm{Ab}$ alone, and 8 (15.4\%) for both. Seventeen patients $(58.6 \%)$ had LC, 26 (50.0\%) Child A, 7 (13.5\%) Child B, and 5 (9.6\%) Child C. Fourteen patients (26.9\%) had diabetes mellitus (DM) and 5 (9.6\%) had gall stones. Preoperative AFP levels were above normal (>15 ng/ml) in 29 patients (55.8\%), CEA levels were above normal $(>5 \mathrm{ng} / \mathrm{ml})$ in 7 patients (13.5\%), and CA 19-9 levels were above normal $(>37 \mathrm{U} / \mathrm{ml})$ in $16(30.8 \%)$. Based on the American Joint Committee on Cancer staging system, at the time of resection, 16 patients $(30.8 \%)$ had stage I tumors, $24(46.2 \%)$ stage II, 8 (15.4\%) stage III and $4(7.7 \%)$ stage IVA. No patient had stage IVB [(any T any $\mathrm{N} \mathrm{M1):} \mathrm{distant} \mathrm{metastasis} \mathrm{(M1)]} \mathrm{disease.}$

\section{Correlation between $\mathrm{MK}$ and clinicopathological characteristics in CHCC-CC patients}

Immunohistochemical staining was performed on 52 paraffin-embedded $\mathrm{CHCC}-\mathrm{CC}$ tissue samples (Figs. 1a-1f). Two-color immunofluorescent staining for CK7 and He1 confirmed both HCC and ICC cell markers were expressed in the serial sections of CHCC-CC (Fig. 2a-c). As can be seen in Table 1,30 of the 52 patients $(57.7 \%)$ positively expressed MK. There were no significant correlations between that expression and gender $(p=0.942)$, age at diagnosis $(p=0.516)$, hepatitis $\mathrm{B}(p=0.679)$, hepatitis $\mathrm{C}(p=0.870)$, liver cirrhosis $(p=0.753)$, diabetes mellitus $(p=0.753)$, gall stone $(p=0.149)$, histological grade $(=0.753)$, lymph-vascular invasion $(p=0.253)$, peri-neural invasion $(p=0.226)$, surgical margin $(p=0.679)$, lymph nodes metastases $(p=1.000)$ or AJCC tumor stage $(p=0.094)$. There was, however, a significant association between high expression of MK protein and clinically advanced T stage (T3/T4 vs T1/T2; $p=0.007)$ (Table 1).

\section{Survival analysis}

Median follow-up was 688 days (87-3374 days). Twenty-four patients died. Median disease free survival was 513 days, two-year disease free survival was $42.1 \%$, and three-year overall survival $44.6 \%$. As shown in Table 2, disease free survival was significantly lower in patients with positive lymph-vascular invasion ( $p=0.022$, Fig. 3a), T stage III/IV $(p<0.001$, Fig. 3b), AJCC tumor staging III/IV $(p<0.001$, Fig. $3 \mathrm{c})$ and MK expression $(p<0.001$, Fig. 3d). Overall survival was also significantly lower in patients with lymph-vascular invasion $(p=0.009$, Fig. 4a). It was also significantly lower in patients with positive lymph-vascular invasion (LVI) $(p=0.009$, Fig. 4a), T3/ 
a

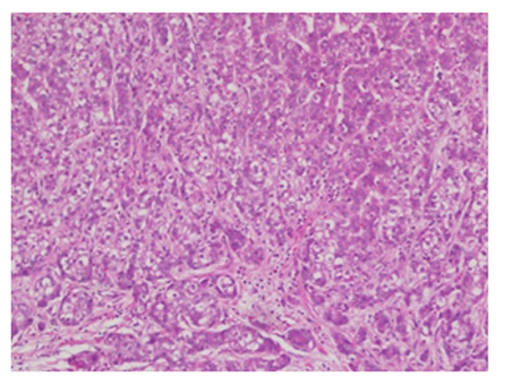

c

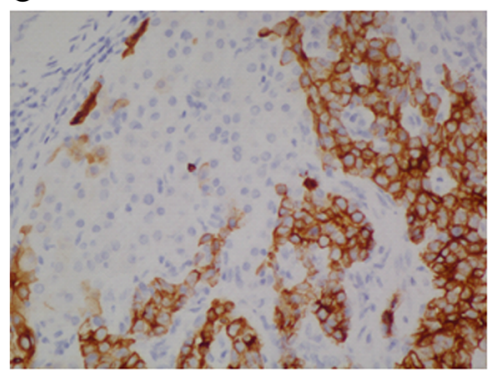

e

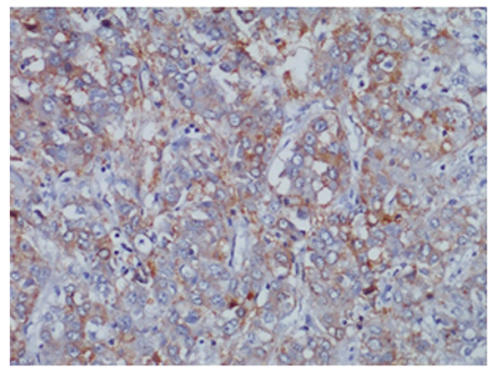

b

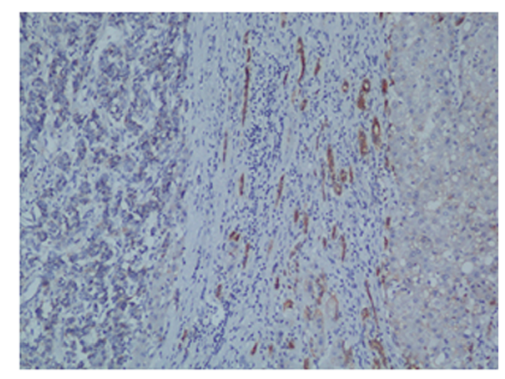

d

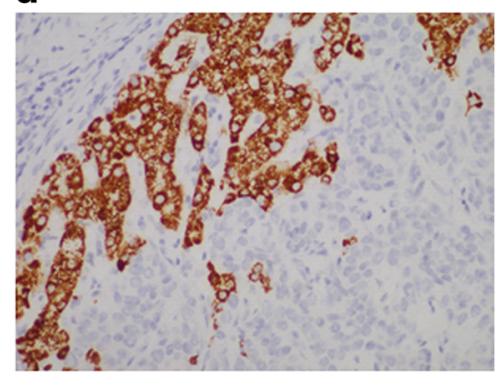

f

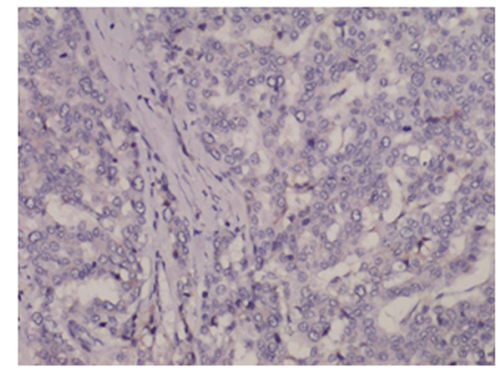

Fig. 1 Pathological features and MK expression in combined hepatocellular cholangiocarcinoma (CHCC-CC). Microscopically, the tumor was diagnosed as CHCC-CC with HE staining (a). Adjacent non-cancerous tissue showed no MK expression (b). Because the HCC component was positive with hep1 but negative with CK7 (c). Conversely, ICC component was positive with CK7 but negative with hep1 (d). Positive MK expression in some CHCC-CC tissues (e). Negative MK expression in some CHCC-CC tissues (f)

4 stage $(p<0.001$, Fig. $4 \mathrm{~b})$, positive $\mathrm{N}$ stage $(p=0.001$, Fig. 4c), AJCC tumor staging III/V $(p=<0.001$, Fig. $4 \mathrm{~d})$ and positive MK expression ( $p=0.012$, Fig. $4 \mathrm{e})$.

Multivariable analysis revealed $\mathrm{T}$ stage and positive MK expression to be independent prognostic factors for disease-free survival after resection $(\mathrm{HR}=8.004$ and $\mathrm{HR}$ $=2.240$; both $p<0.001$ ) (Table 2) and AJCC tumor stage was found to be an independent prognostic factor for overall survival $(\mathrm{HR}=12.784, p<0.001)$ (Table 3$)$.

\section{Discussion}

The incidence of CHCC-CC, a rare tumor, varies among different studies. The actual incidence may be higher than usually reported for two reasons. First, because most patients have either no symptoms or non-specific symptoms, clinical presentation does not generally contribute to diagnosis. Second, patients with $\mathrm{CHCC}-\mathrm{CC}$ frequently present more advanced disease stages than those with typical HCC, and so a high percentage of patients with $\mathrm{CHCC}-\mathrm{CC}$ do not receive surgical resection [28]. It is very difficult to make accurate diagnosis of CHCC-CC before surgery, because $\mathrm{CT}$ or MRI scans often do not show typical patterns of contrast uptake or washout. CHCC-CC may have CT features of both HCC and CC when a hepatic tumor contains an area of hyper-enhancement in the early phase and an area of delayed enhancement in the late phase on dynamics CT [29]. It may also have features of both when a hypovascular liver tumor is associated with significant elevation of afetoprotein levels and multiple regional lymph nodes metastases [30], or when a hepatic tumor has hypervascular expression and elevation of serum CEA and carbohydrate antigen 199. Although histological studies may be able to identify a dominant tumor type, they usually fail to detect the presence of both $\mathrm{CHCC}$ 
a

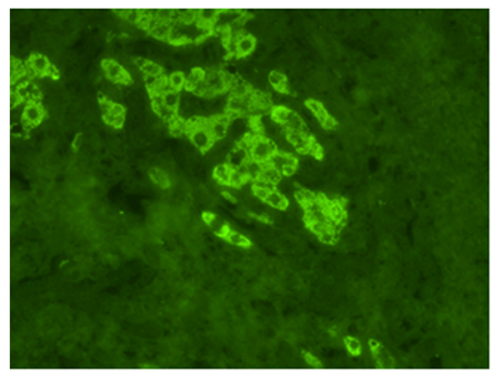

C

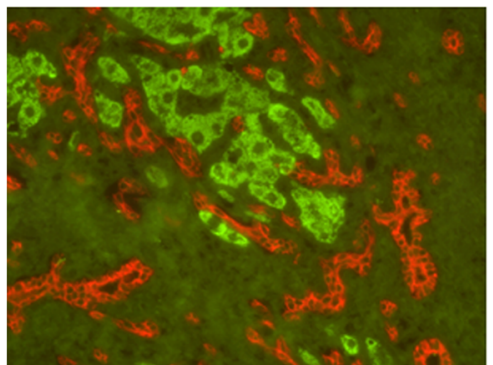

b
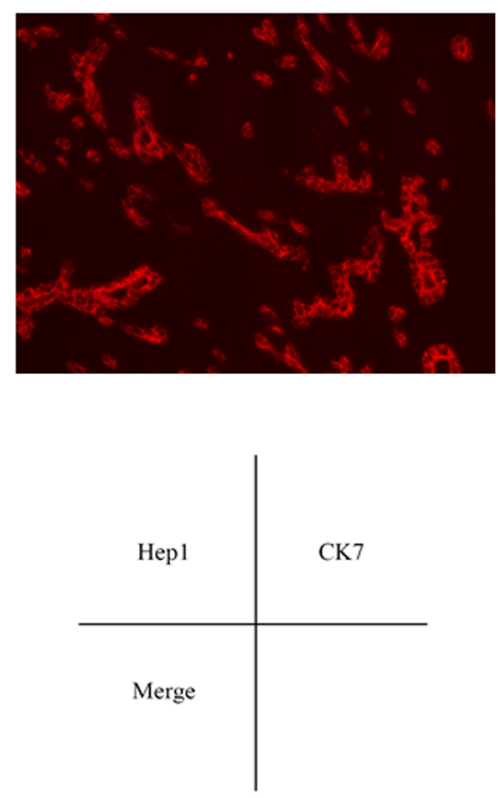

Fig. 2 Two-color immunofluorescent staining for CK7 and Hep1 in the CHCC-CC patient samples. Hep1 (a), CK7 (b) and two color immunofluorescent stain merge $(\mathbf{c})$

and CC. Therefore, precise diagnosis of $\mathrm{CHCC}-\mathrm{CC}$ before surgery remains a challenge.

Some studies report CHCC-CC to have a worse prognosis than either HCC or CC alone [3, 9]. Similarly, our $52 \mathrm{CHCC}-\mathrm{CC}$ patients, who had received intensive curative tumor resection, had a two-year disease free survival of $42.1 \%$ (median 17.3 months) and a three-year overall survival of $44.6 \%$ (median 22.9 months). Because most of the CHCC-CC patients in this study were male patients with a high prevalence of $\mathrm{HBV}$, chronic $\mathrm{HBV}$ infection may be a major cause for both HCC and CHCC-CC in Taiwan. The factors predicting survival also vary among different studies, possibly due to the limited number of patients [12]. Univariate analyses performed by prior studies found overall survival to be significantly related to microscopic vascular invasion, bilobar tumors and tumors $>6 \mathrm{~cm}$ [9], vascular invasion and satellite lesions [3], and lymph node metastases. Univariate analysis of our patients' data found LVI, T stage IIIIV, AJCC tumor stage III-IV and positive midkine expression to be associated with poorer disease free and overall survival. Our multivariate analysis revealed AJCC tumor stage III-IV to be the most important predictor of both survival rates. These findings are consistent with previous CHCC-CC studies $[3,31$, 32].

In this study, positive expression of $\mathrm{MK}$ in tumors was associated with poor prognosis and reduced survival in $\mathrm{CHCC}-\mathrm{CC}$ patients, suggesting that MK could potentially be used as an independent post-surgical prognostic biomarker for $\mathrm{CHCC}-\mathrm{CC}$. MK expression predicted poor prognosis in disease free survival in both our univariate and multivariate analyses. Yoon et al. [33] attributed poor overall survival in this population to shorter survival after recurrence. Although our multivariate analysis did not find a significant association between MK expression and overall survival, our univariate analysis did, though the small number of cases may have affected this result.

MK, a heparin-binding growth factor, plays a central role in chemotaxis, angiogenesis, and the inhibition of apoptosis. The expression of MK is elevated in various tumors [34], and has been described as a potential prognostic marker in several malignancies, including esophageal cancer [35], endometrial carcinoma [36] and gastric cancer [37]. One study found breast cancer patients to have higher plasma levels of midkine than their healthy controls [38]. Another study also found a correlation between MK protein expression and malignant status and prognosis of breast cancer patients [39]. Zhu et al. found serum MK levels to be clearly increased in hepatocellular cancer patients and suggested they could be used to diagnose hepatocellular cancer with a high sensitivity. Moreover, serum MK levels, which were reported by one study to be markedly decreased in hepatocellular cancer patients after curative resection, were found by the same study to re-increased when tumors recurred [40]. Keto et al. also reported MK to be increased at 
Table 1 Relationships between midkine expression and clinicopathological factors

\begin{tabular}{|c|c|c|c|}
\hline Midkine & $\begin{array}{l}\text { Negative } \\
\text { expression }\end{array}$ & $\begin{array}{l}\text { Positive } \\
\text { expression }\end{array}$ & $P$ \\
\hline \multicolumn{4}{|l|}{ Age } \\
\hline$<60$ & $15(53.6 \%)$ & $13(46.4 \%)$ & \multirow[t]{2}{*}{0.516} \\
\hline$\geq 60$ & $15(62.5 \%)$ & $9(37.5 \%)$ & \\
\hline \multicolumn{4}{|l|}{ Gender } \\
\hline Male & $22(59.5 \%)$ & $15(40.5 \%)$ & \multirow[t]{2}{*}{0.924} \\
\hline Female & $8(53.3 \%)$ & $7(46.7 \%)$ & \\
\hline \multicolumn{4}{|l|}{ Hepatitis B } \\
\hline Negative & $11(64.7 \%)$ & $6(35.3 \%)$ & \multirow[t]{2}{*}{0.679} \\
\hline Positive & 19 (54.3\%) & $16(45.7 \%)$ & \\
\hline \multicolumn{4}{|l|}{ Hepatitis C } \\
\hline Negative & $20(55.6 \%)$ & $16(44.4 \%)$ & \multirow[t]{2}{*}{0.870} \\
\hline Positive & $10(62.5 \%)$ & $6(37.5 \%)$ & \\
\hline \multicolumn{4}{|l|}{ Liver cirrhosis } \\
\hline No cirrhosis & $9(64.3 \%)$ & $5(35.7 \%)$ & \multirow[t]{2}{*}{0.753} \\
\hline Cirrhosis & $21(55.3 \%)$ & $17(44.7 \%)$ & \\
\hline \multicolumn{4}{|l|}{ DM } \\
\hline Negative & $21(55.3 \%)$ & $17(44.7 \%)$ & \multirow[t]{2}{*}{0.753} \\
\hline Positive & $9(64.3 \%)$ & $5(35.7 \%)$ & \\
\hline \multicolumn{4}{|l|}{ Gall stone } \\
\hline Negative & $29(61.7 \%)$ & $18(38.3 \%)$ & \multirow[t]{2}{*}{0.149} \\
\hline Positive & $1(20.0 \%)$ & $4(80.0 \%)$ & \\
\hline \multicolumn{4}{|l|}{ CEA } \\
\hline$\leq 5$ & $27(60.0 \%)$ & $18(40.0 \%)$ & \multirow[t]{2}{*}{0.438} \\
\hline$>5$ & $3(42.9 \%)$ & $4(57.1 \%)$ & \\
\hline \multicolumn{4}{|l|}{ CA-199 } \\
\hline$\leq 35$ & $20(55.6 \%)$ & $16(44.4 \%)$ & \multirow[t]{2}{*}{0.870} \\
\hline$>35$ & $10(62.5 \%)$ & $6(37.5 \%)$ & \\
\hline \multicolumn{4}{|l|}{ AFP } \\
\hline$\leq 15$ & $12(52.2 \%)$ & $11(47.8 \%)$ & \multirow[t]{2}{*}{0.473} \\
\hline$>15$ & $18(62.1 \%)$ & $11(37.9 \%)$ & \\
\hline \multicolumn{4}{|l|}{ Histology grade } \\
\hline Well and moderately & $21(55.3 \%)$ & $17(44.7 \%)$ & \multirow[t]{2}{*}{0.753} \\
\hline Poorly & $9(64.3 \%)$ & $5(35.7 \%)$ & \\
\hline \multicolumn{4}{|l|}{ LVI } \\
\hline Negative & $21(63.3 \%)$ & $12(36.4 \%)$ & \multirow[t]{2}{*}{0.253} \\
\hline Positive & $9(47.4 \%)$ & $10(52.6 \%)$ & \\
\hline \multicolumn{4}{|l|}{ PNI } \\
\hline Negative & 25 (54.3\%) & $21(45.7 \%)$ & \multirow[t]{2}{*}{0.226} \\
\hline Positive & $5(83.3 \%)$ & $1(16.7 \%)$ & \\
\hline Surgical margin & & & \\
\hline$<10 \mathrm{~mm}$ & 19 (54.3\%) & $16(45.7 \%)$ & 0.679 \\
\hline$\geq 10 \mathrm{~mm}$ & $11(64.7 \%)$ & $6(35.3 \%)$ & \\
\hline
\end{tabular}

Table 1 Relationships between midkine expression and clinicopathological factors (Continued)

\begin{tabular}{llll}
\hline Midkine & $\begin{array}{l}\text { Negative } \\
\text { expression }\end{array}$ & $\begin{array}{l}\text { Positive } \\
\text { expression }\end{array}$ & $P$ \\
\hline T stage & $28(66.7 \%)$ & $14(33.3 \%)$ & $0.007^{*}$ \\
T1-T2 & $2(20.0 \%)$ & $8(80.0 \%)$ & \\
T3-T4 & $28(57.1 \%)$ & $21(42.9 \%)$ & 1.000 \\
N stage & $2(66.7 \%)$ & $1(33.3 \%)$ & \\
Negative & & & \\
Positive & & $14(35.0 \%)$ & 0.094 \\
AJCC staging & $26(65.0 \%)$ & $8(66.7 \%)$ & \\
I-II & $4(33.3 \%)$ & & \\
III-IV & & & \\
\hline DM diabetes Mellitus, LVI lymph-vascular invasion, PNI peri-neural invasion
\end{tabular}

DM diabetes Mellitus, LVI lymph-vascular invasion, $P N I$ peri-neural invasion

messenger RNA and protein levels in patients with intrahepatic cholangiocarcinoma, although they stated that the ultimate biological significance and their possible relationship to tumor behavior had not been established. To the best of our knowledge, the current study is the first to report the results of $\mathrm{MK}$ immunohistochemical analysis of CHCC-CC tissue.

Cancer stem cell markers have been correlated with poor prognosis in primary liver malignancy and their presence has been associated with carcinogenesis, vascular invasion, and metastasis in this disease [41-43]. Therefore, the 2010 WHO classification divides CHCC-CC into two subtypes: the classical type and subtypes with stem cell features [44]. Classical type CHCC-CC includes HCC areas, CC areas and transitional zones, which comprise tumor cells with stem cell features. MK is known to have the ability to induce epithelial mesenchymal transition (EMT) in some types of cancer cells, the differentiation of lost polarity in epithelial cells and cell adhesion to contractile and motile mesenchymal cells [45]. In addition to angiogenesis, Takenaka et al. found that the growth of mouse embryonic stem cells could be induced while MK inhibits apoptosis through the PI3K/Akt signaling pathway [46]. Zhao et al. reported that mesenchymal stem cells overexpressing MK transplantation stimulate vasculogenesis effectively by increasing pro-angiogenesis factors (VEGF, TGF- $\beta$ ). These findings suggest that $\mathrm{MK}$ might be involved in the pathogenesis of liver cancers with stemness. Our study showed the patients with $\mathrm{CHCC}-\mathrm{CC}$ who had a positive expression of $\mathrm{MK}$ to be at much higher risk of early recurrence and poor survival. However, currently $M K$ is still not a suitable as therapeutic target and drugs need to be developed for this in the future.

This study has several limitations. First, it was based on a retrospective analysis of data collected from only 52 patients accumulated over a short 
Table 2 Correlation between the clinicopathological features and 2-year progression-free survival in combined hepatocellular cholangiocarcinoma

\begin{tabular}{|c|c|c|c|c|c|}
\hline Variables & No. of patients & $\begin{array}{l}\text { Cumulative } \\
2 \text { - year progression-free survival rate }\end{array}$ & $P$ & HR $(95 \% \mathrm{Cl})$ & $P$ \\
\hline \multicolumn{6}{|l|}{ Age } \\
\hline$<60$ & 28 & $38.5 \%$ & 0.941 & & \\
\hline$\geqq 60$ & 24 & $35.6 \%$ & & & \\
\hline \multicolumn{6}{|l|}{ Gender } \\
\hline Male & 37 & $35.8 \%$ & 0.097 & & \\
\hline Female & 15 & $59.3 \%$ & & & \\
\hline \multicolumn{6}{|l|}{ Hepatitis B } \\
\hline Negative & 17 & $39.7 \%$ & 0.632 & & \\
\hline Positive & 35 & $44.9 \%$ & & & \\
\hline \multicolumn{6}{|l|}{ Hepatitis C } \\
\hline Negative & 36 & $42.5 \%$ & 0.747 & & \\
\hline Positive & 16 & $41.5 \%$ & & & \\
\hline \multicolumn{6}{|l|}{ Liver cirrhosis } \\
\hline No cirrhosis & 14 & $55.1 \%$ & 0.479 & & \\
\hline Cirrhosis & 38 & $39.2 \%$ & & & \\
\hline \multicolumn{6}{|l|}{ DM } \\
\hline Negative & 38 & $44.7 \%$ & 0.575 & & \\
\hline Positive & 14 & $37.5 \%$ & & & \\
\hline \multicolumn{6}{|l|}{ Gall stone } \\
\hline Negative & 47 & $45.2 \%$ & 0.178 & & \\
\hline Positive & 5 & $20.0 \%$ & & & \\
\hline \multicolumn{6}{|l|}{ CEA } \\
\hline$\leq 5$ & 45 & $44.3 \%$ & 0.311 & & \\
\hline$>5$ & 7 & $34.3 \%$ & & & \\
\hline \multicolumn{6}{|l|}{ CA-199 } \\
\hline$\leq 35$ & 36 & $43.7 \%$ & 0.535 & & \\
\hline$>35$ & 16 & $19.3 \%$ & & & \\
\hline \multicolumn{6}{|l|}{ AFP } \\
\hline$\leq 15$ & 23 & $26.6 \%$ & 0.978 & & \\
\hline$>15$ & 29 & $43.5 \%$ & & & \\
\hline \multicolumn{6}{|l|}{ Histology grade } \\
\hline Well or Moderate & 38 & $44.9 \%$ & 0.499 & & \\
\hline Poorly & 14 & $40.8 \%$ & & & \\
\hline \multicolumn{6}{|l|}{ LVI } \\
\hline Negative & 33 & $50.4 \%$ & $0.022^{*}$ & & \\
\hline Positive & 19 & $15.0 \%$ & & & \\
\hline \multicolumn{6}{|l|}{ PNI } \\
\hline Negative & 46 & $44.1 \%$ & 0.377 & & \\
\hline Positive & 6 & $33.3 \%$ & & & \\
\hline \multicolumn{6}{|l|}{ Surgical margin } \\
\hline$<10 \mathrm{~mm}$ & 35 & $35.4 \%$ & 0.746 & & \\
\hline$\geq 10 \mathrm{~mm}$ & 17 & $41.6 \%$ & & & \\
\hline
\end{tabular}


Table 2 Correlation between the clinicopathological features and 2-year progression-free survival in combined hepatocellular cholangiocarcinoma (Continued)

\begin{tabular}{|c|c|c|c|c|c|}
\hline Variables & No. of patients & $\begin{array}{l}\text { Cumulative } \\
2 \text { - year progression-free survival rate }\end{array}$ & $P$ & HR $(95 \% \mathrm{Cl})$ & $P$ \\
\hline \multicolumn{6}{|l|}{ T stage } \\
\hline TI-II & 42 & $52.3 \%$ & $<0.001^{*}$ & $8.004(2.869-22.336)$ & $<0.001^{*}$ \\
\hline TIII-IV & 10 & $0 \%$ & & & \\
\hline \multicolumn{6}{|l|}{ N stage } \\
\hline Negative & 49 & $43.3 \%$ & 0.223 & $4.701(0.952-23.203)$ & 0.057 \\
\hline Positive & 3 & $33.3 \%$ & & & \\
\hline \multicolumn{6}{|l|}{ AJCC staging } \\
\hline$|-| \mid$ & 40 & $53.2 \%$ & $<0.001^{*}$ & & \\
\hline III-IV & 12 & $8.3 \%$ & & & \\
\hline \multicolumn{6}{|c|}{ Midkine expression } \\
\hline Negative & 30 & $60.5 \%$ & $<0.001^{*}$ & 4.238 (1.900-9.449) & $<0.001^{*}$ \\
\hline Positive & 22 & $8.5 \%$ & & & \\
\hline
\end{tabular}

Cl confidence interval, $H R$ hazard ratio

a

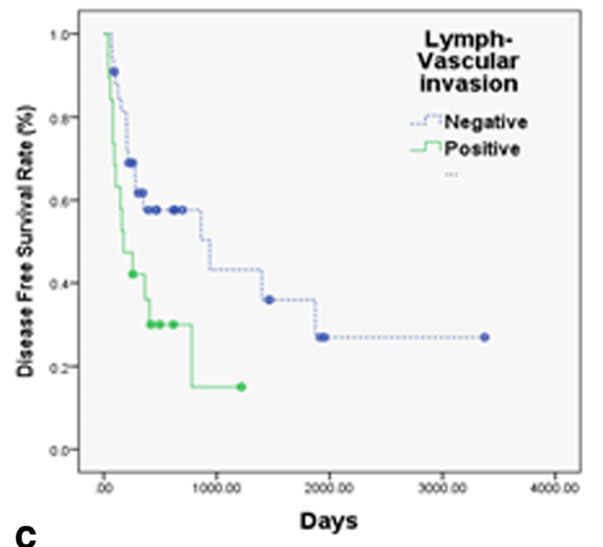

C

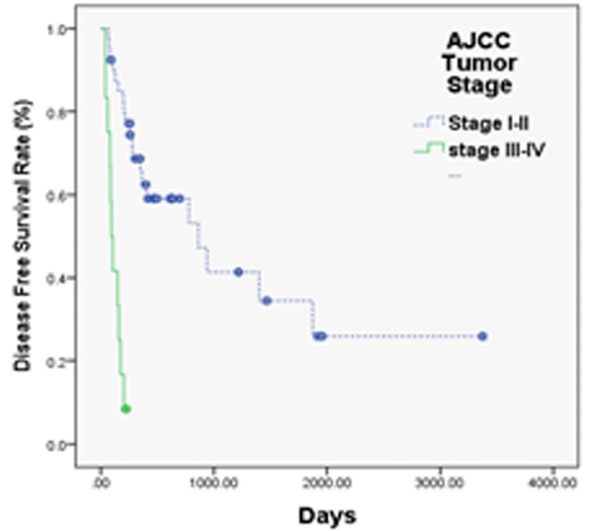

b
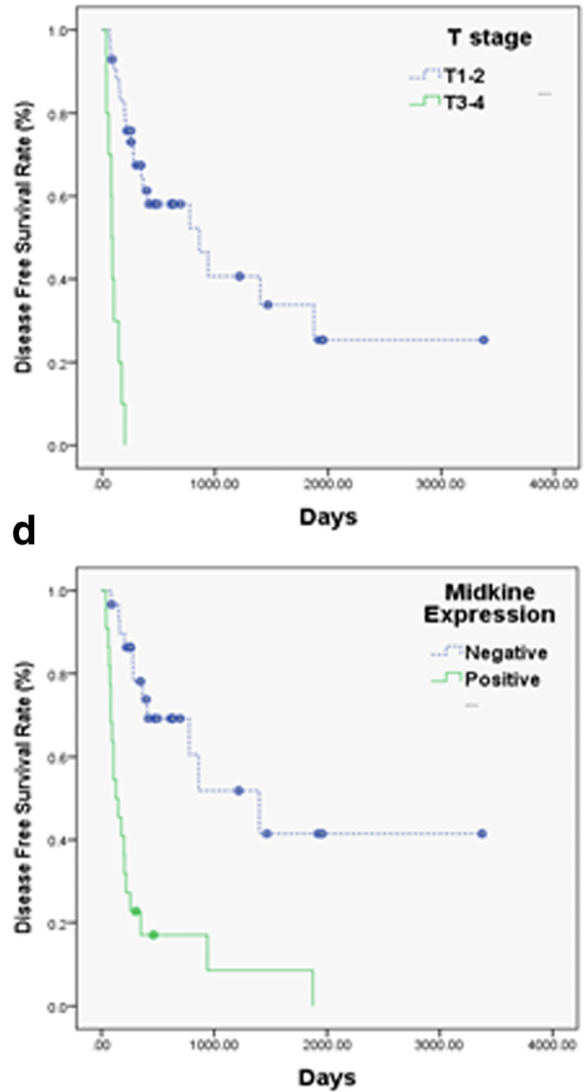

Fig. 3 Kaplan-Meier estimates of the probability of disease free survival (DFS). Positive Lymph-vascular invasion (LVI) (a), T-stage III/IV (b), AJCC tumor stage III/IV (c) and Positive MK expression (d) were associated with poor DFS 
a

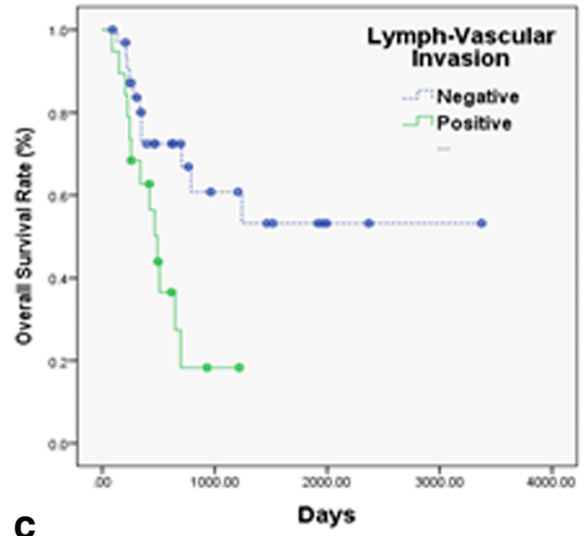

C
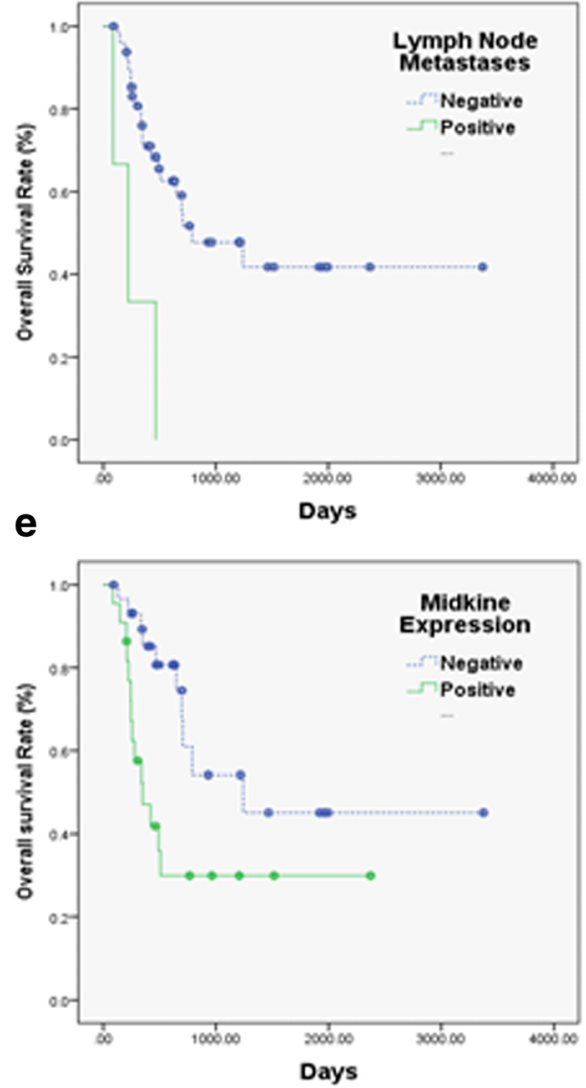

b
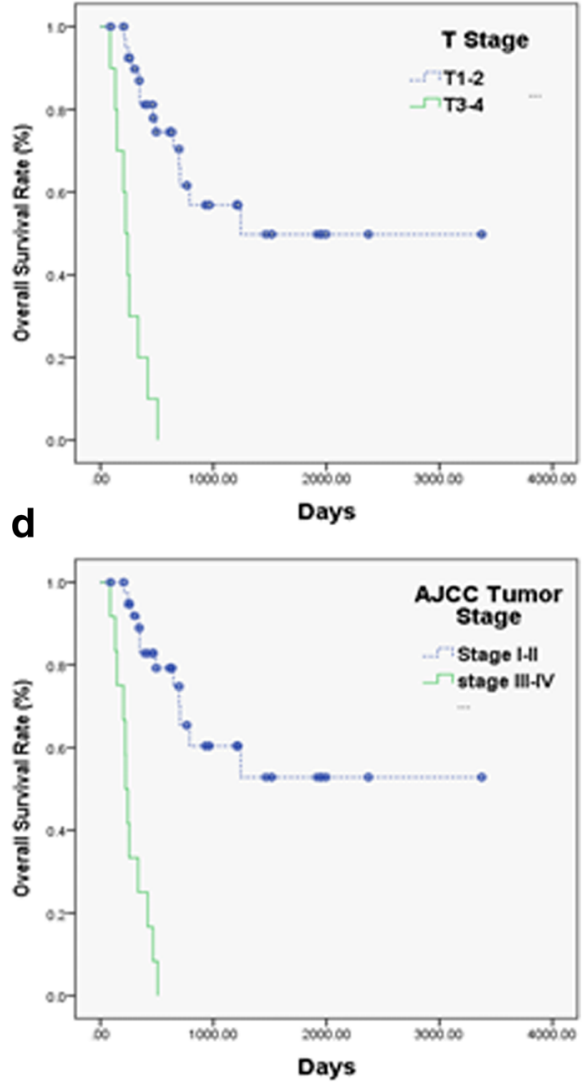

Fig. 4 Kaplan-Meier estimates of the probability of overall survival (OS). Positive lymph-vascular invasion (LVI) (a), T stage III/IV (b), Node positive (c), AJCC tumor staging III/NI (d) and positive MK expression (e) had poorer OS

period. Second, only three enrolled CHCC-CC patients had regional lymph node metastases. Preoperative diagnosis for patients with CHCC-CC is very difficult because there is no typical pattern of contrast uptake or washout in dynamic CT or MRI scans. In our series, most patients were diagnosed as having HCC before surgery. Patients who are found to have image study evidence of lymph node involvement before treatment often receive systemic treatment instead of hepatectomies, since HCC with lymph node metastases post curative resection has been reported to have poor disease free and overall survival [47]. Third, therapies used to treat recurrent CHCC-CC may affect overall survival. Some studies showed the recurrence rates following resections of these tumors were high and these recurrent tumors were 
Table 3 Correlation between the clinicopathological features and 3-year overall survival in combined hepatocellular cholangiocarcinoma

\begin{tabular}{|c|c|c|c|c|c|}
\hline Variables & No. of patients & $\begin{array}{l}\text { Cumulative } \\
\text { 3- year Overall survival rate }\end{array}$ & $P$ & $\mathrm{HR}(95 \% \mathrm{Cl})$ & $P$ \\
\hline \multicolumn{6}{|l|}{$\overline{\text { Age }}$} \\
\hline$<60$ & 28 & $46.1 \%$ & 0.962 & & \\
\hline$\geqq 60$ & 24 & $41.9 \%$ & & & \\
\hline \multicolumn{6}{|l|}{ Gender } \\
\hline Male & 37 & $41.7 \%$ & 0.531 & & \\
\hline Female & 15 & $58.8 \%$ & & & \\
\hline \multicolumn{6}{|l|}{ Hepatitis B } \\
\hline Negative & 17 & $15.1 \%$ & 0.208 & & \\
\hline Positive & 35 & $58.8 \%$ & & & \\
\hline \multicolumn{6}{|l|}{ Hepatitis C } \\
\hline Negative & 36 & $49.4 \%$ & 0.548 & & \\
\hline Positive & 16 & $29.8 \%$ & & & \\
\hline \multicolumn{6}{|l|}{ Liver cirrhosis } \\
\hline No cirrhosis & 14 & $49.9 \%$ & 0.649 & & \\
\hline Cirrhosis & 38 & $45.7 \%$ & & & \\
\hline \multicolumn{6}{|l|}{ DM } \\
\hline Negative & 38 & $44.5 \%$ & 0.816 & & \\
\hline Positive & 14 & $44.9 \%$ & & & \\
\hline \multicolumn{6}{|l|}{ Gall stone } \\
\hline Negative & 47 & $49.7 \%$ & 0.109 & & \\
\hline Positive & 5 & $0 \%$ & & & \\
\hline \multicolumn{6}{|l|}{ CEA } \\
\hline$\leq 5$ & 45 & $48.6 \%$ & 0.052 & & \\
\hline$>5$ & 7 & $0 \%$ & & & \\
\hline \multicolumn{6}{|l|}{ CA-199 } \\
\hline$\leq 35$ & 36 & $52.6 \%$ & 0.069 & & \\
\hline$>35$ & 16 & $24.6 \%$ & & & \\
\hline \multicolumn{6}{|l|}{ AFP } \\
\hline$\leq 15$ & 23 & $42.7 \%$ & 0.825 & & \\
\hline$>15$ & 29 & $45.6 \%$ & & & \\
\hline \multicolumn{6}{|l|}{ Histology grade } \\
\hline Well or Moderate & 38 & $49.3 \%$ & 0.328 & & \\
\hline Poorly & 14 & $22.4 \%$ & & & \\
\hline \multicolumn{6}{|l|}{ LVI } \\
\hline Negative & 33 & $60.8 \%$ & $0.009^{*}$ & & \\
\hline Positive & 19 & $18.3 \%$ & & & \\
\hline \multicolumn{6}{|l|}{ PNI } \\
\hline Negative & 46 & $48.2 \%$ & 0.060 & & \\
\hline Positive & 6 & $0 \%$ & & & \\
\hline \multicolumn{6}{|l|}{ Surgical margin } \\
\hline$<10 \mathrm{~mm}$ & 35 & $41.2 \%$ & 0.552 & & \\
\hline$\geq 10 \mathrm{~mm}$ & 17 & $61.6 \%$ & & & \\
\hline
\end{tabular}


Table 3 Correlation between the clinicopathological features and 3-year overall survival in combined hepatocellular cholangiocarcinoma (Continued)

\begin{tabular}{|c|c|c|c|c|c|}
\hline Variables & No. of patients & $\begin{array}{l}\text { Cumulative } \\
\text { 3- year Overall survival rate }\end{array}$ & $P$ & HR $(95 \% \mathrm{Cl})$ & $P$ \\
\hline \multicolumn{6}{|l|}{ T stage } \\
\hline TI-II & 42 & $56.9 \%$ & $<0.001^{*}$ & & \\
\hline TIII-IV & 10 & $0 \%$ & & & \\
\hline \multicolumn{6}{|l|}{$N$ stage } \\
\hline Negative & 49 & $47.7 \%$ & $0.001^{*}$ & & \\
\hline Positive & 3 & $0 \%$ & & & \\
\hline \multicolumn{6}{|c|}{ AJCC staging } \\
\hline$|-| \mid$ & 40 & $60.4 \%$ & $<0.001^{*}$ & $12.784(4.822-33.481)$ & $<0.001^{*}$ \\
\hline III-IV & 12 & $0 \%$ & & & \\
\hline \multicolumn{6}{|c|}{ Midkine expression } \\
\hline Negative & 30 & $54.2 \%$ & $0.012^{*}$ & & \\
\hline Positive & 22 & $29.9 \%$ & & & \\
\hline
\end{tabular}

$\mathrm{Cl}$ confidence interval, $H R$ hazard ratio

commonly detected in the remnant liver [12]. Salvage treatment can include surgery, trans-arterial embolization, percutaneous ethanol injection, and radiofrequency ablation.

\section{Conclusions}

In conclusion, the findings of the present study suggest that heparin-binding growth factor MK contributes to the clinical outcome in patients with resectable $\mathrm{CHCC}$ CC. It is significantly elevated in patients with advanced T-stage CHCC-CC. A high level of MK protein independently predicts a poor prognosis for patients receiving surgery for this disease.

\section{Acknowledgements}

The authors thank Kaohsiung Chang Gung Memorial Hospital Cancer Center for collecting the patients' clinical data.

\section{Funding}

This study was funded by grant obtained by Dr. Yen-Yang Chen from Kaohsiung Chang Gung Memorial Hospital Taiwan for the design of the study and the collection of patient samples (Grant CMRPG8E0881). This study was also funded by grants obtained by Dr. Tai-Jan Chiu from Kaohsiung Chang Gung Memorial Hospital Taiwan for data analyses and interpretation (Grants CMRPG8C0531 and CMRPG8D0801).

\section{Availability of data and materials}

The datasets used and/or analyzed during the current study are available from the corresponding author upon reasonable request.

\section{Authors' contributions}

MCM, TJC and YCC conceived the study design, carried out and coordinated immunohistochemical examinations of tumor specimens and data analysis, and drafted the manuscript. YJC and $J L$ participated in the interpretation of data and conducted immunohistochemistry analysis. CTL and HHT collected the clinical data of patients and performed statistical data analysis. YYC coordinated the study and was involved in drafting the manuscript and revising it critically. All authors read and approved the final manuscript.
Ethics approval and consent to participate

This study followed the World Medical Association Declaration of Helsinki recommendation and was approved by the Chang Gung Medical Foundation Institutional Review Board. Informed consent was obtained in written form from study all participants and the protocol for this study was approved by the Institutional Review Boards of Chang-Gung Medical Center (Taiwan) (IRB 103-7412B). Moreover, because this study was retrospective study in design and used archived material, it did not pose increased risk to the patients.

\section{Consent for publication}

Not applicable.

\section{Competing interests}

The authors declare that they have no competing interests.

\section{Publisher's Note}

Springer Nature remains neutral with regard to jurisdictional claims in published maps and institutional affiliations.

\section{Author details \\ ${ }^{1}$ Division of Hematology-Oncology, Department of Internal Medicine, Kaohsiung Chang Gung Memorial Hospital, 123 Ta-Pei Road, Niaosong District, Kaohsiung 833, Taiwan. ${ }^{2}$ Chang Gung University College of Medicine, Kaohsiung, Taiwan. ${ }^{3}$ Department of Anatomic Pathology, E-Da hospital, I-Shou University, Kaohsiung, Taiwan. ${ }^{4}$ Kaohsiung Chang Gung Cholangiocarcinoma and Pancreatic Cancer Group, Cancer Center, Kaohsiung Chang Gung Memorial Hospital, Kaohsiung, Taiwan. ${ }^{5}$ Institute of Clinical Medical Sciences, Chang Gung University, Kaohsiung 833, Taiwan. ${ }^{6}$ Department of Pathology, Kaohsiung Chang Gung Memorial Hospital, Chang Gung University College of Medicine, Kaohsiung, Taiwan. ${ }^{7}$ Department of Nursing, Kaohsiung Chang Gung Memorial Hospital Cancer Center, Kaohsiung Chang Gung Memorial Hospital, Kaohsiung, Taiwan.}

Received: 23 January 2017 Accepted: 19 February 2018

Published online: 27 February 2018

\section{References}

1. Goodman ZD, Ishak KG, Langloss JM, Sesterhenn IA, Rabin L. Combined hepatocellular-cholangiocarcinoma. A histologic and immunohistochemical study. Cancer. 1985;55:124-35.

2. Allen RA, Lisa JR. Combined liver cell and bile duct carcinoma. Am J Pathol. 1949;25:647-55. 
3. Jarnagin WR, Weber S, Tickoo SK, Koea JB, Obiekwe S, et al. Combined hepatocellular and cholangiocarcinoma: demographic, clinical, and prognostic factors. Cancer. 2002;94:2040-6.

4. Liu CL, Fan ST, Lo CM, Ng IO, Lam CM, et al. Hepatic resection for combined hepatocellular and cholangiocarcinoma. Arch Surg. 2003;138:86-90.

5. Liver Cancer Study Group of J. Primary liver cancer in Japan. Clinicopathologic features and results of surgical treatment. Ann Surg. 1990; 211:277-87.

6. Maeda T, Adachi E, Kajiyama K, Sugimachi K, Tsuneyoshi M. Combined hepatocellular and cholangiocarcinoma: proposed criteria according to cytokeratin expression and analysis of clinicopathologic features. Hum Pathol. 1995;26:956-64.

7. $\mathrm{Ng} \mathrm{IO}$, Shek TW, Nicholls J, Ma LT. Combined hepatocellularcholangiocarcinoma: a clinicopathological study. J Gastroenterol Hepatol. 1998;13:34-40.

8. Taguchi J, Nakashima O, Tanaka M, Hisaka T, Takazawa T, et al. A clinicopathological study on combined hepatocellular and cholangiocarcinoma. J Gastroenterol Hepatol. 1996;11:758-64.

9. Yano Y, Yamamoto J, Kosuge T, Sakamoto Y, Yamasaki S, et al. Combined hepatocellular and cholangiocarcinoma: a clinicopathologic study of 26 resected cases. Jpn J Clin Oncol. 2003;33:283-7.

10. Zhang F, Chen XP, Zhang W, Dong HH, Xiang S, et al. Combined hepatocellular cholangiocarcinoma originating from hepatic progenitor cells: immunohistochemical and double-fluorescence immunostaining evidence. Histopathology. 2008;52:224-32.

11. Tickoo SK, Zee SY, Obiekwe S, Xiao H, Koea J, et al. Combined hepatocellular-cholangiocarcinoma: a histopathologic, immunohistochemical, and in situ hybridization study. Am J Surg Pathol. 2002;26:989-97.

12. Yap $A Q$, Chen CL, Yong CC, Kuo FY, Wang SH, et al. Clinicopathological factors impact the survival outcome following the resection of combined hepatocellular carcinoma and cholangiocarcinoma. Surg Oncol. 2013;22:55-60.

13. Kim R, Kim SB, Cho EH, Park SH, Park SB, et al. CD44 expression in patients with combined hepatocellular cholangiocarcinoma. Ann Surg Treat Res. 2015;89:9-16.

14. Kim GJ, Kim H, Park YN. Increased expression of Yes-associated protein 1 in hepatocellular carcinoma with stemness and combined hepatocellularcholangiocarcinoma. PLoS One. 2013;8:e75449.

15. Muramatsu T, Kadomatsu K. Midkine: an emerging target of drug development for treatment of multiple diseases. Br J Pharmacol. 2014;171: 811-3.

16. Ota $\mathrm{K}$, Fujimori $\mathrm{H}$, Ueda $\mathrm{M}$, Jono $\mathrm{H}$, Shinriki $\mathrm{S}$, et al. Midkine expression is correlated with an adverse prognosis and is down-regulated by p53 in oral squamous cell carcinoma. Int J Oncol. 2010;37:797-804.

17. Ren YJ, Zhang QY. Expression of midkine and its clinical significance in esophageal squamous cell carcinoma. World J Gastroenterol. 2006;12:2006-10.

18. Salama RH, Muramatsu H, Zou P, Okayama M, Muramatsu T. Midkine, a heparin-binding growth factor, produced by the host enhances metastasis of Lewis lung carcinoma cells. Cancer Lett. 2006;233:16-20.

19. Rawnaq T, Dietrich L, Wolters-Eisfeld G, Uzunoglu FG, Vashist YK, et al. The multifunctional growth factor midkine promotes proliferation and migration in pancreatic cancer. Mol Cancer Res. 2014;12:670-80.

20. Luo J, Wang $X$, Xia Z, Yang L, Ding Z, et al. Transcriptional factor specificity protein 1 (SP1) promotes the proliferation of glioma cells by up-regulating midkine (MDK). Mol Biol Cell. 2015:26:430-9.

21. Sakamoto K, Kadomatsu K. Midkine in the pathology of cancer, neural disease, and inflammation. Pathol Int. 2012;62:445-55.

22. Chiu TJ, Chen YJ, Rau KM, Chen CH, Chien CY, et al. Midkine neurite growth-promoting factor 2 expression as a potential prognostic marker of adjuvant therapy in head and neck squamous cell carcinoma. Biomarkers. 2013;18:687-98.

23. Shimada H, Nabeya $Y$, Tagawa M, Okazumi S, Matsubara $H$, et al. Preoperative serum midkine concentration is a prognostic marker for esophageal squamous cell carcinoma. Cancer Sci. 2003;94:628-32.

24. Yuan K, Chen Z, Li W, Gao CE, Li G, et al. MDK protein overexpression correlates with the malignant status and prognosis of non-small cell lung cancer. Arch Med Res. 2015;46:635-41.

25. Kato M, Shinozawa T, Kato S, Awaya A, Terada T. Increased midkine expression in hepatocellular carcinoma. Arch Pathol Lab Med. 2000; 124:848-52.
26. Kato M, Shinozawa T, Kato S, Endo K, Terada T. Increased midkine expression in intrahepatic cholangiocarcinoma: immunohistochemical and in situ hybridization analyses. Liver. 2000;20:216-21.

27. Greene FL, American Joint Committee on Cancer, American Cancer Society. AJCC cancer staging handbook : from the AJCC cancer staging manual. New York: Springer; 2002. p. xv. 469

28. Kim KH, Lee SG, Park EH, Hwang S, Ahn CS, et al. Surgical treatments and prognoses of patients with combined hepatocellular carcinoma and cholangiocarcinoma. Ann Surg Oncol. 2009;16:623-9.

29. Sanada Y, Shiozaki S, Aoki H, Takakura N, Yoshida K, et al. A clinical study of 11 cases of combined hepatocellular-cholangiocarcinoma assessment of enhancement patterns on dynamics computed tomography before resection. Hepatol Res. 2005;32:185-95.

30. Toh CH, Cheung YC, Ng SH, Lin CY, Chan SC, et al. Combined hepatocellular-cholangiocarcinoma: a case report. Int J Clin Pract. 2004;58: 1170-3.

31. Lee SD, Park SJ, Han SS, Kim SH, Kim YK, et al. Clinicopathological features and prognosis of combined hepatocellular carcinoma and cholangiocarcinoma after surgery. Hepatobiliary Pancreat Dis Int. 2014;13: 594-601.

32. Lin G, Toh CH, Wu RC, Ko SF, Ng SH, et al. Combined hepatocellular cholangiocarcinoma: prognostic factors investigated by computed tomography/magnetic resonance imaging. Int J Clin Pract. 2008; 62:1199-205.

33. Yoon Yl, Hwang S, Lee YJ, Kim KH, Ahn CS, et al. Postresection outcomes of combined hepatocellular carcinoma-cholangiocarcinoma, hepatocellular carcinoma and intrahepatic cholangiocarcinoma. J Gastrointest Surg. 2016; 20:411-20.

34. Kadomatsu K, Kishida S, Tsubota S. The heparin-binding growth factor midkine: the biological activities and candidate receptors. J Biochem. 2013; 153:511-21.

35. Shimada H, Nabeya Y, Okazumi S, Matsubara H, Kadomatsu K, et al. Increased serum midkine concentration as a possible tumor marker in patients with superficial esophageal cancer. Oncol Rep. 2003;10:411-4.

36. Tanabe K, Matsumoto M, Ikematsu S, Nagase S, Hatakeyama A, et al. Midkine and its clinical significance in endometrial carcinoma. Cancer Sci. 2008:99:1125-30.

37. Obata Y, Kikuchi S, Lin Y, Yagyu K, Muramatsu T, et al. Serum midkine concentrations and gastric cancer. Cancer Sci. 2005;96:54-6.

38. Ibusuki M, Fujimori H, Yamamoto Y, Ota K, Ueda M, et al. Midkine in plasma as a novel breast cancer marker. Cancer Sci. 2009;100:1735-9.

39. Li F, Tian P, Zhang J, Kou C. The clinical and prognostic significance of midkine in breast cancer patients. Tumour Biol. 2015;36:9789-94.

40. Zhu WW, Guo JJ, Guo L, Jia HL, Zhu M, et al. Evaluation of midkine as a diagnostic serum biomarker in hepatocellular carcinoma. Clin Cancer Res. 2013:19:3944-54.

41. Komuta M, Spee B, Vander Borght S, De Vos R, Verslype C, et al. Clinicopathological study on cholangiolocellular carcinoma suggesting hepatic progenitor cell origin. Hepatology. 2008;47:1544-56.

42. Villanueva A, Hoshida Y, Toffanin S, Lachenmayer A, Alsinet C, et al. New strategies in hepatocellular carcinoma: genomic prognostic markers. Clin Cancer Res. 2010;16:4688-94.

43. Cai X, Zhai J, Kaplan DE, Zhang Y, Zhou L, et al. Background progenitor activation is associated with recurrence after hepatectomy of combined hepatocellular-cholangiocarcinoma. Hepatology. 2012;56:1804-16.

44. Li ZS, Li Q. The latest 2010 WHO classification of tumors of digestive system. Zhonghua Bing Li Xue Za Zhi. 2011:40:351-4.

45. Gungor C, Zander H, Effenberger KE, Vashist YK, Kalinina T, et al. Notch signaling activated by replication stress-induced expression of midkine drives epithelial-mesenchymal transition and chemoresistance in pancreatic cancer. Cancer Res. 2011;71:5009-19.

46. Takenaka H, Horiba M, Ishiguro H, Sumida A, Hojo M, et al. Midkine prevents ventricular remodeling and improves long-term survival after myocardial infarction. Am J Physiol Heart Circ Physiol. 2009;296:H462-9.

47. Lee CW, Chan KM, Lee CF, Yu MC, Lee WC, et al. Hepatic resection for hepatocellular carcinoma with lymph node metastasis: clinicopathological analysis and survival outcome. Asian J Surg. 2011;34:53-62. 